\title{
Development of niosomal formulations loaded with cyclosporine A and evaluation of its compatibility
}

\author{
Mujeeb Ur Rehman ${ }^{1}$, Akhtar Rasul ${ }^{1 *}$, Muhammad Imran Khan², Muhammad \\ Hanif $^{3}$, Muhammad Naeem Aamir ${ }^{1}$, Muhammad Khurram Waqas ${ }^{4}$, Misbah \\ Hameed ${ }^{1}$, Muhammad Rouf Akram ${ }^{5}$ \\ ${ }^{1}$ Faculty of Pharmaceutical Sciences, Department of Pharmaceutics, Government College University Faisalabad, ${ }^{2}$ Riphah \\ Institute of Pharmaceutical Sciences, Riphah International University Lahore. ${ }^{3}$ Faculty of Pharmacy, Bahauddin Zakariya \\ University, Multan, ${ }^{4}$ Institute of Pharmaceutical Sciences, University of Veterinary and Animal Sciences, Lahore, ${ }^{5}$ College of \\ Pharmacy, University of Sargodha, Sargodha, Pakistan
}

*For correspondence: Email: akhtar.rasul@gcuf.edu.pk; Tel: 0092-3344918888

\begin{abstract}
Purpose: To formulate niosomes of cyclosporine $A$ using nonionic surfactants, and to use the attenuated total reflectance/Fourier transform infrared (ATR-FTIR) technique to explore solid/liquid interfacial phenomena as well as compatibility between active drug and pharmaceutical excipients.

Methods: Niosomes of cyclosporine A were prepared using the thin-film hydration method. Cholesterol and non-ionic surfactants, including polyethylene glycol sorbitan monostearate (Tween 60) and sorbitan monostearate (Span 60), were used as excipients. The ATR-FTIR spectra of all the ingredients, their physical mixtures, and niosomal formulations were studied. The niosomes were characterized for size, polydispersivity index (PDI), zeta potential, and entrapment efficiency.

Results: Six niosomal formulations $\left(F_{1}-F_{6}\right)$ were successfully developed. Niosomal formulation $F_{2}$ prepared at the ratio of 6:4 surfactant to cholesterol, presented the highest entrapment efficiency of $77.28 \%$. The ATR-FTIR spectra of niosomal formulations did not show incompatibility. The size of the selected formulation $\left(F_{2}\right)$ was $1049 \mathrm{~nm}$ while its SEM image displayed a spherical nature of the niosomes.

Conclusion: The results show that cyclosporine $A$ can be entrapped in niosomes using non-ionic surfactants and cholesterol. Furthermore, there is no significant interaction between the ingredients of niosomes and cyclosporine $A$.
\end{abstract}

Keywords: Cyclosporine A, Attenuated total reflectance Fourier transform infrared spectroscopy), Niosomes, Compatibility, Non-ionic surfactants

This is an Open Access article that uses a funding model which does not charge readers or their institutions for access and distributed under the terms of the Creative Commons Attribution License (http://creativecommons.org/licenses/by/4.0) and the Budapest Open Access Initiative (http://www.budapestopenaccessinitiative.org/read), which permit unrestricted use, distribution, and reproduction in any medium, provided the original work is properly credited.

Tropical Journal of Pharmaceutical Research is indexed by Science Citation Index (SciSearch), Scopus, International Pharmaceutical Abstract, Chemical Abstracts, Embase, Index Copernicus, EBSCO, African Index Medicus, JournalSeek, Journal Citation Reports/Science Edition, Directory of Open Access Journals (DOAJ), African Journal Online, Bioline International, Open-J-Gate and Pharmacy Abstracts

\section{INTRODUCTION}

In the last few decades, scientists have developed an interest in the formulations of surfactant vesicles to improve drug delivery systems. Nanocarriers of drugs such as niosomes are formulated, which can act as "magic bullets" to target affected cells and organs [1]. 
Among different immunosuppressant drugs available, cyclosporine $A$ is of unique importance. The structure of cyclosporine A contains cyclic peptide comprising of 11 amino acids (cyclic endecapeptide). Cyclosporine $A$ is a strong immunosuppressive drug used primarily to decrease rejection after kidney, heart, lungs, liver, pancreas, and bone marrow transplants. It is also used for the prevention and cure of graftversus-host-disease, aplastic anemia, severe psoriasis and eczema, and is used in rheumatoid arthritis of a severe nature, when second-line therapy is not available. Its usual dose in organ transplantation is from $10 \mathrm{mg} / \mathrm{kg}$ to $15 \mathrm{mg} / \mathrm{kg}$ per day for seven to fourteen days after the operation, and then the dose is reduced slowly from $2 \mathrm{mg} / \mathrm{kg}$ to $6 \mathrm{mg} / \mathrm{kg}$ per day as a maintenance dose. The therapeutic index of cyclosporine $A$ is low, and it has many toxic effects which include gastrointestinal intolerance, hepatotoxicity, nephrotoxicity, and certain neurological issues $[2,3]$.

Cyclosporine $A$ is a white powder. It is not soluble in water, but it is soluble in ethyl alcohol, methyl alcohol or methanol, acetone, chloroform, ether, and dichloromethane. In saturated hydrocarbons, cyclosporine $A$ is slightly soluble [4]. After oral administration, its absolute bioavailability and pharmacokinetics are variable, due to its less absorption. To increase the solubility of less water-soluble drugs and to increase the in vivo absorption of drugs, the microemulsion system was developed [5]. The oil-based formulation of cyclosporine A (Sandimmune) results in poor bioavailability and variable results in different patients. The bioavailability of cyclosporine $A$ is also reduced due to its pre-systemic metabolism in the liver and gut wall. Sandiummune Neoral is a microemulsion-based formulation, and it provides high bioavailability through the oral route. Research is being conducted to further improve its bioavailability. Liposomes with sodium deoxycholate provide high entrapment efficiency to cyclosporine $A$ and increased bioavailability in comparison to conventional liposomes and microemulsion-based formulations [6]. Furthermore, if we prepare niosomes of cyclosporine $A$, the problems associated with liposomal formulation of cyclosporine $\mathrm{A}$ can be resolved, and the bioavailability and dissolution profile of cyclosporine A can be improved with reduced side effects. Therefore, various niosomal formulations have been prepared to increase the solubility profile of cyclosporine $A$ and to increase its availability at the site of absorption.
To study the chemical interactions in biological studies at solid/liquid interfaces, the ATR-FTIR technique is widely used. It evaluates the compatibility and possible interactions within ingredients of niosomal formulations [8].

\section{EXPERIMENTAL}

\section{Materials}

Cyclosporine A was obtained from Xi'an Lyphar Biotech Co., Ltd. Polyethylene glycol sorbitan monostearate (Tween 60), Sorbitan monostearate (Span 60), Polyethylene glycol sorbitan monooleate (Tween 80), and Sorbitone monooleate (Span 80) were purchased from Daejung Chemicals \& Metals Co., Ltd. Cholesterol, and 1-hexadecyl pyridinium chloride monohydrate was obtained from Alfa Aesar GmbH \& Co. KG, Germany. Phosphate buffered saline tablets were obtained from Oxoid Ltd, England. In the laboratory, fresh distilled water was prepared by employing a distillation apparatus. Chloroform and methyl alcohol were obtained from Daejung Chemicals \& Metals Co., Ltd, Korea.

\section{Preparation of physical mixtures}

A mortar and pestle was used to prepare physical mixtures by mixing equimolar amounts of cyclosporine A, nonionic surfactants, and cholesterol. For physical mixture 1 (PM1) cholesterol, Polyethylene glycol sorbitan monostearate also known as Tween 60, cyclosporine $A$, and Sorbitan monostearate also known as Span 60 were mixed together, while, for physical mixture 2 (PM2), cholesterol, Polyethylene glycol sorbitan monooleate also known as Tween 80, cyclosporine $\mathrm{A}$, and Sorbitone monooleate also known as Span 80 were mixed together in equimolar ratio $(1: 1: 1: 1)$.

The ingredients of the mixture were mixed in a mortar for approximately ten to fifteen minutes so that a homogenous mixture was achieved.

\section{Preparation of niosomal formulation}

Niosomal formulations of cyclosporine A were prepared along with non-ionic amphiphiles such as Polyethylene glycol sorbitan monostearate, also known as Tween 60, and Sorbitone monooleate, also known as Span 80, and so on, and cholesterol using thin-film hydration method. The composition of niosomal formulations is given in Table 1. In thin-film hydration method the drug/non-ionic surfactants and cholesterol were mixed in chloroform/methanol (2:1). When these ingredients were mixed in the solvent, the 
Table 1: Composition of niosomal formulations

\begin{tabular}{lccccc}
\hline $\begin{array}{l}\text { Formulation } \\
\text { code }\end{array}$ & $\begin{array}{c}\text { Surfactants } \mathbf{( m g )} \\
\text { Tween 60 }\end{array}$ & Span 60 & $\begin{array}{c}\text { Cholesterol } \\
(\mathbf{m g})\end{array}$ & $\begin{array}{c}\text { Molar ratio } \\
\text { (Surfactant: } \\
\text { Cholesterol) }\end{array}$ & $\begin{array}{c}\text { Total } \boldsymbol{\mu m o l} \text { of } \\
\text { lipid contents }\end{array}$ \\
\hline F1 & 229 & 75.36 & 57.99 & $7: 3$ & 500 \\
F2 & 196.35 & 64.59 & 77.33 & $6: 4$ & 500 \\
F3 & 163.62 & 53.83 & 96.66 & $5: 5$ & 500 \\
& $\underline{\text { Tween } 80}$ & Span 80 & & & 500 \\
F4 & 229.25 & 75 & 57.99 & $7: 3$ & 500 \\
F5 & 196.50 & 64.29 & 77.33 & $6: 4$ & 500 \\
F6 & 163.75 & 53.57 & 96.66 & $5: 5$ & \\
\hline
\end{tabular}

Each formulation contained $25 \mathrm{mg}(21 \mu$ moles $)$ of the drug

solution was put in the rotary evaporator at 57 ${ }^{\circ} \mathrm{C}$, and it was allowed to evaporate until a thin film was formed on the wall of flask. Then for one hour, this thin film was hydrated with $20 \mathrm{~mL}$ of phosphate buffer saline ( $\mathrm{pH}$ 7.4) in a water bath using gentle stirring at $60^{\circ} \mathrm{C}$. Consequently, the niosomal preparations were stored in a refrigerator at $4-8{ }^{\circ} \mathrm{C}$ overnight, so that the niosomes matured [9].

\section{ATR-FTIR spectroscopic studies}

The spectra of cyclosporine $A$, non-ionic amphiphiles, cholesterol, physical mixture 1 and 2 , and formulations of niosomes were taken from FTIR Spectrophotometer (Thermo nicolet 6700, USA) in the wave number range of $4000-500$ $\mathrm{cm}^{-1}$. For scanning pike, the single bounce attenuated total reflectance (ATR) method was used.

\section{Characterization of niosomes}

\section{Size and zeta potential}

The size, polydispersity index (PDI), and zeta potential were determined by using Malvern zetasizer, version 7.11. It gives size distribution report by intensity.

\section{Morphological features}

The shape and morphology were studied using the field emission, scanning electron microscope. For the niosomal formulation, a drop is taken and placed on an aluminum stub using adhesive silver tape. Aluminum stubs were placed in a vacuum overnight and then sputter coated, in the process of which gold was used [10].

\section{Drug entrapment studies}

The niosomes loaded with cyclosporine A were separated by ultracentrifugation at $12000 \times \mathrm{g}$ for thirty minutes at $4{ }^{\circ} \mathrm{C}$. The supernatant was separated, and niosomes were disrupted using methanol [11]. High pressure liquid chromatography was used to determine the amount of cyclosporine $A$ in niosomal formulations. [12,13]. Nucleosil C18 column was used. Water and acetonitrile in ratio 3:7 and v/v were used in the mobile phase. The mobile phase was filtered through a $0.45-\mu \mathrm{m}$ membrane filter, and a syringe filter of nylon $0.45 \mu \mathrm{m}$ was used to filter samples. Acetonitrile can dissolve the cellulose filters, consequently, nylon filters were used instead. The flow rate $1.0 \mathrm{ml} / \mathrm{min}$ was taken, and at $210 \mathrm{~nm}$, the effluents were monitored [14].

\section{Statistical analysis}

One-way analysis of variance (ANOVA) was conducted at $95 \%$ confidence interval using GraphPad Prism 6 software. The significance level was set to $p<0.05$. It is used to compare the mean values of niosomes size and entrapment efficiencies of six niosomal formulations, and it is used to determine statistical significance.

\section{RESULTS}

ATR-FTIR spectra of components of niosmal formulation are shown in Figure 1. The components are (A) Cyclosporine A, (B) Cholesterol, (C) Sorbitan monostearate (Span 60), (D) Sorbitone monooleate (Span 80), (E) Polyethylene glycol sorbitan monostearate (Tween 60), (F) Polyethylene glycol sorbitan monooleate (Tween 80), and (G) Hexa decyl pyridinium chloride. Characteristic peaks of individual components are shown in Table 2 The characteristic peaks in the FTIR spectrum of cyclosporine A, cholesterol, Span 60, Span 80, Tween 60 , and Tween 80 and are similar to peaks as given in literature, which indicates the purity of samples and the fact that they are suitable for niosomal formulations.

ATR-FTIR spectra of physical mixtures (PM1 and PM2) are shown in Figure 2. It shows similar peaks in the spectra of physical mixtures as in the individual spectrum of pure ingredients. 


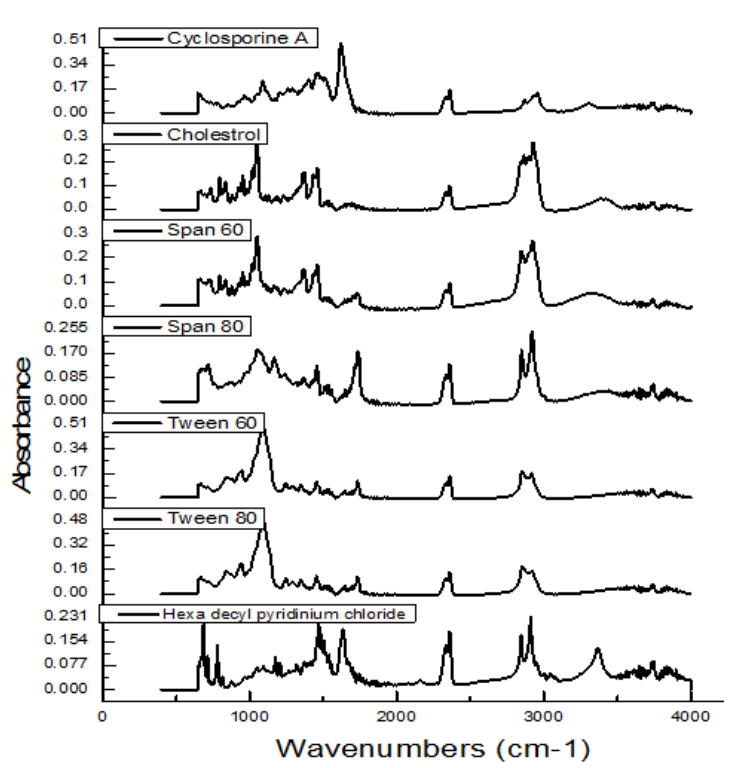

Figure 1: ATR-FTIR spectra of individual components

Characteristic peaks of physical mixtures are depicted in Table 3. No significant shifts of peaks were observed. Consequently, it was observed that there were no interactions between the ingredients.

The ATR-FTIR spectra of niosomal formulations (F1, F2, F3, F4, F5, and F6) are shown in Figure 3.In the spectra of niosomal formulation, most of the peaks are diffused, demonstrating a strong physical interaction between cholesterol, cyclosporine A, and surfactants. Characteristic peaks of niosomal formulations are given in Table 4. No significant shifts of new peaks were observed which indicates that no chemical interaction is present.

\section{FTIR spectrum of cyclosporine A}

Briefly, the characteristic peaks in spectra of cyclosporine $A$ were at $3310 \mathrm{~cm}^{-1}, 2957 \mathrm{~cm}^{-1}$, $1621 \mathrm{~cm}^{-1}$, and $1091 \mathrm{~cm}^{-1}$, which indicates amines, carboxylic acid, amides, and the alkyl substituted ether functional group respectively.

The characteristic peaks of $2360 \mathrm{~cm}^{-1}$ which indicate the primary and secondary amines functional group were found in the FTIR spectrum of cholesterol, cyclosporine A, Span 60, Span 80, Tween 60, Tween 80, hexa decyl pyridinium chloride, physical mixture 1 and 2, and also in formulation 1, 4, and 5.

The characteristic peaks of $1457 \mathrm{~cm}^{-1}, 1458 \mathrm{~cm}$ 1 , and $1459 \mathrm{~cm}^{-1}$ which indicate alkanes and the aromatic ring stretch functional group were found in Tween 80, cholesterol, Span 80, cyclosporine A, Span 60, physical mixture 1 and 2, and in formulation 1 and 5 .
Table 2: Characteristic peaks of individual components

\begin{tabular}{|c|c|c|}
\hline Component & $\begin{array}{c}\text { Characteristic } \\
\text { peak }\left(\mathrm{cm}^{-1}\right)\end{array}$ & Functional group \\
\hline \multirow{7}{*}{$\begin{array}{l}\text { Cyclosporine } \\
\text { A }\end{array}$} & 3310 & Amines or hydroxyl group \\
\hline & 2957 & Carboxylic acids \\
\hline & 2360 & $\begin{array}{l}\text { Primary and secondary } \\
\text { amines }\end{array}$ \\
\hline & 1621 & Amides, Conjugated ketone \\
\hline & 1457 & $\begin{array}{l}\text { Alkanes, Aromatic ring } \\
\text { stretch }\end{array}$ \\
\hline & 1091 & $\begin{array}{l}\text { Amines, Alkyl substituted } \\
\text { ether }\end{array}$ \\
\hline & 967 & Alkenes \\
\hline \multirow[t]{4}{*}{ Cholesterol } & 3420 & Hydroxy group \\
\hline & 2929 & Carboxylic acids \\
\hline & 2360 & $\begin{array}{l}\text { Primary and secondary } \\
\text { amines }\end{array}$ \\
\hline & 1459 & $\begin{array}{l}\text { Alkanes, Aromatic ring } \\
\text { stretch }\end{array}$ \\
\hline \multirow[t]{6}{*}{ Span 60} & 3310 & Amines or hydroxyl group \\
\hline & 2926 & Carboxylic acids \\
\hline & 2360 & $\begin{array}{l}\text { Primary and secondary } \\
\text { amines }\end{array}$ \\
\hline & 1733 & Aldehyde \\
\hline & 1459 & $\begin{array}{l}\text { Alkanes, Aromatic ring } \\
\text { stretch }\end{array}$ \\
\hline & 1052 & $\begin{array}{l}\text { Cyclohexane ring vibrations, } \\
\text { Alkyl substituted ether }\end{array}$ \\
\hline \multirow[t]{5}{*}{ Span 80} & 2921 & Carboxylic acids \\
\hline & 2360 & $\begin{array}{l}\text { Primary and secondary } \\
\text { amines }\end{array}$ \\
\hline & 1736 & Esters \\
\hline & 1457 & $\begin{array}{l}\text { Alkanes, Aromatic ring } \\
\text { stretch }\end{array}$ \\
\hline & 1054 & $\begin{array}{l}\text { Cyclohexane ring vibrations, } \\
\text { Alkyl substituted ether }\end{array}$ \\
\hline \multirow[t]{4}{*}{ Tween 60} & 2920 & Carboxylic acids \\
\hline & 2360 & $\begin{array}{l}\text { Primary and secondary } \\
\text { amines }\end{array}$ \\
\hline & 1734 & Aldehyde \\
\hline & 1092 & $\begin{array}{l}\text { Amines, Alkyl substituted } \\
\text { ether }\end{array}$ \\
\hline \multirow[t]{5}{*}{ Tween 80} & 2856 & Carboxylic acids \\
\hline & 2360 & $\begin{array}{l}\text { Primary and secondary } \\
\text { amines }\end{array}$ \\
\hline & 1734 & Aldehyde \\
\hline & 1457 & $\begin{array}{l}\text { Alkanes, Aromatic ring } \\
\text { stretch }\end{array}$ \\
\hline & 1091 & $\begin{array}{l}\text { Amines, Alkyl substituted } \\
\text { ether }\end{array}$ \\
\hline \multirow{6}{*}{$\begin{array}{l}\text { Hexa decyl } \\
\text { pyridinium } \\
\text { chloride }\end{array}$} & 3367 & Amines or hydroxyl group \\
\hline & 2912 & Carboxylic acids \\
\hline & 2360 & $\begin{array}{l}\text { Primary and secondary } \\
\text { amines }\end{array}$ \\
\hline & 1635 & $\begin{array}{l}\text { Secondary amine, } \\
\text { Conjugated ketone }\end{array}$ \\
\hline & 1471 & $\begin{array}{l}\text { Methylene } \mathrm{C}-\mathrm{H} \text { bend, } \\
\text { carbonate ion }\end{array}$ \\
\hline & 1177 & Secondary amine \\
\hline
\end{tabular}




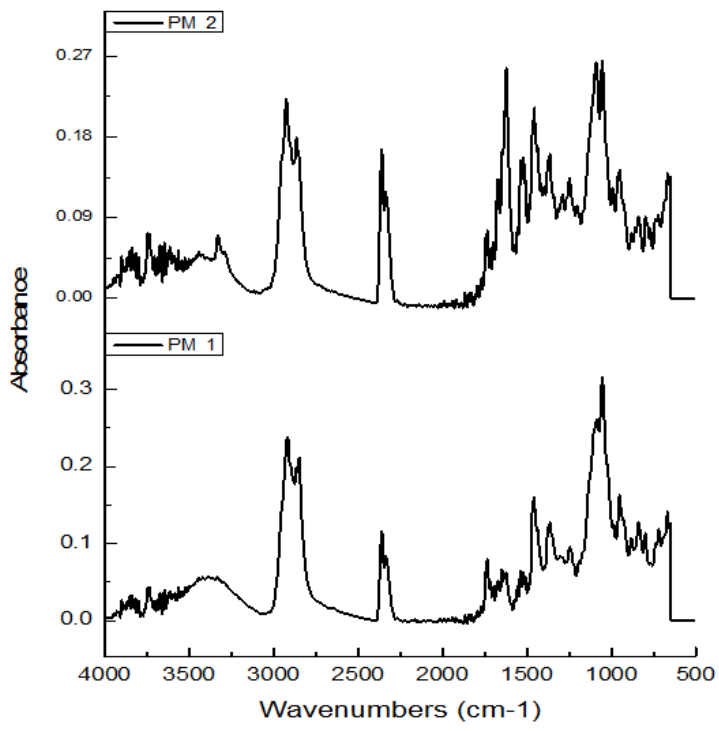

Figure 2: ATR-FTIR spectra of physical mixture 1 (PM1) and physical mixture 2 (PM2)

Table 3: Characteristic peaks of physical mixtures

\begin{tabular}{|c|c|c|}
\hline $\begin{array}{l}\text { Physical } \\
\text { mixture }\end{array}$ & $\begin{array}{c}\text { Characteristic } \\
\text { peak }\left(\mathrm{cm}^{-1}\right)\end{array}$ & Functional group \\
\hline \multirow[t]{6}{*}{ PM1 } & 3420 & Hydroxy group \\
\hline & 2919 & Carboxylic acids \\
\hline & 2360 & $\begin{array}{l}\text { Primary and } \\
\text { secondary amines }\end{array}$ \\
\hline & 1734 & Aldehyde \\
\hline & 1458 & $\begin{array}{l}\text { Alkanes, Aromatic } \\
\text { ring stretch }\end{array}$ \\
\hline & 1054 & $\begin{array}{l}\text { Cyclohexane ring } \\
\text { vibrations, } \\
\text { Alkyl substituted } \\
\text { ether }\end{array}$ \\
\hline \multirow[t]{7}{*}{ PM 2} & 2927 & Carboxylic acids \\
\hline & 2360 & $\begin{array}{l}\text { Primary and } \\
\text { secondary amines }\end{array}$ \\
\hline & 1622 & $\begin{array}{l}\text { Secondary amine, } \\
\text { Conjugated ketone }\end{array}$ \\
\hline & 1457 & $\begin{array}{l}\text { Alkanes, Aromatic } \\
\text { ring stretch }\end{array}$ \\
\hline & 1091 & $\begin{array}{l}\text { Amines, Alkyl } \\
\text { substituted ether }\end{array}$ \\
\hline & 1054 & $\begin{array}{l}\text { Cyclohexane ring } \\
\text { vibrations, } \\
\text { Alkyl substituted } \\
\text { ether }\end{array}$ \\
\hline & 951 & Alkenes \\
\hline
\end{tabular}

The characteristic peaks of $1091 \mathrm{~cm}^{-1}$ and 1092 $\mathrm{cm}^{-1}$ which indicate amines and alkyl substituted ether functional groups were found in cyclosporine A, Tween 60 , and 80 and physical mixture 2.

\section{FTIR spectra of excipients}

In short, the characteristic peaks in spectra of cholesterol were at $3420 \mathrm{~cm}^{-1}$ and $2929 \mathrm{~cm}^{-1}$, which indicates the hydroxy group and the carboxylic acid functional group respectively.

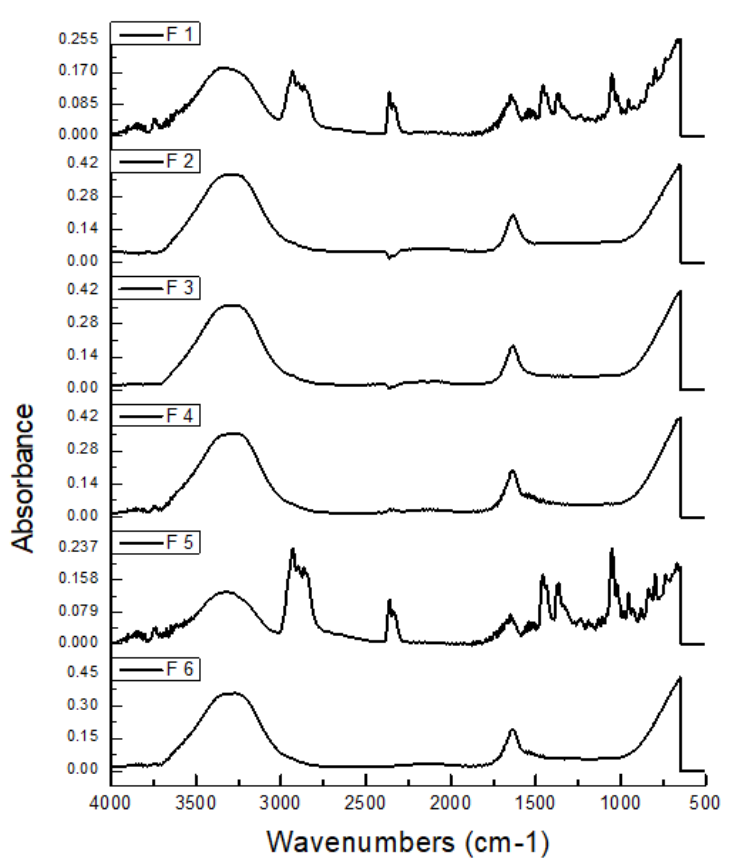

Figure 3: ATR-FTIR spectra of niosomal formulations (F1, F2, F3, F4, F5, and F6).

Table 4: Characteristic peaks of niosomal formulation

\begin{tabular}{|c|c|c|}
\hline $\begin{array}{l}\text { Formu- } \\
\text { lations }\end{array}$ & $\begin{array}{l}\text { Characte- } \\
\text { ristic peak }\end{array}$ & Functional group \\
\hline \multirow[t]{6}{*}{ F1 } & 3336 & Hydroxy group, Carboxylic acids \\
\hline & 2930 & Carboxylic acids \\
\hline & 2360 & Primary and secondary amines \\
\hline & 1649 & Secondary amine \\
\hline & 1457 & Alkanes, Aromatic ring stretch \\
\hline & 1052 & $\begin{array}{l}\text { Cyclohexane ring vibrations, } \\
\text { Alkyl substituted ether }\end{array}$ \\
\hline \multirow[t]{2}{*}{$\mathrm{F} 2$} & 3299 & Hydroxy group, Carboxylic acids \\
\hline & 1631 & $\begin{array}{l}\text { Secondary amine, Conjugated } \\
\text { ketone }\end{array}$ \\
\hline \multirow[t]{2}{*}{ F3 } & 3259 & Hydroxy group, Carboxylic acids \\
\hline & 1635 & $\begin{array}{l}\text { Secondary amine, Conjugated } \\
\text { ketone }\end{array}$ \\
\hline \multirow[t]{3}{*}{4} & 3262 & Hydroxy group, Carboxylic acids \\
\hline & 2359 & Primary and secondary amines \\
\hline & 1636 & $\begin{array}{l}\text { Secondary amine, Conjugated } \\
\text { ketone }\end{array}$ \\
\hline \multirow[t]{6}{*}{ F5 } & 3322 & Hydroxy group \\
\hline & 2929 & Carboxylic acids \\
\hline & 2360 & Primary and secondary amines \\
\hline & 1649 & $\begin{array}{l}\text { Secondary amine, Conjugated } \\
\text { ketone }\end{array}$ \\
\hline & 1458 & Alkanes, Aromatic ring stretch \\
\hline & 1021 & $\begin{array}{l}\text { Cyclohexane ring vibrations, } \\
\text { Alkyl substituted ether }\end{array}$ \\
\hline \multirow[t]{2}{*}{ F6 } & 3273 & Hydroxy group, Carboxylic acids \\
\hline & 1636 & $\begin{array}{l}\text { Secondary amine, Conjugated } \\
\text { ketone }\end{array}$ \\
\hline
\end{tabular}

The characteristic peaks of $2920 \mathrm{~cm}^{-1}, 2921 \mathrm{~cm}^{-}$ $1,2926 \mathrm{~cm}^{-1}$, and $2929 \mathrm{~cm}^{-1}$, which indicate the carboxylic acid functional group were found in Tween 60, Span 80, Span 60, and cholesterol 
respectively. The physical mixture 1 and 2 shows characteristics peaks $2919 \mathrm{~cm}^{-1}$ and $2927 \mathrm{~cm}^{-1}$, and the formulations 1 and 5 shows characteristics peak of $2930 \mathrm{~cm}^{-1}$ and $2929 \mathrm{~cm}^{-1}$, which indicate the carboxylic acid functional group. The characteristic peaks in spectra of Span 60 were at $3310 \mathrm{~cm}^{-1}$ and $2926 \mathrm{~cm}^{-1}$ which indicate amines or the hydroxyl group and the carboxylic acids functional group respectively.

The characteristic peak in spectra of Span 60 and Formulation 1 was at $1052 \mathrm{~cm}^{-1}$, and the characteristic peak in spectra of Span 80, physical mixture 1 and 2 was at 1054, both of these peaks indicate the alkyl substituted ether functional group. Also, the characteristic peak in spectra of Span 60 was at $1733 \mathrm{~cm}^{-1}$, the characteristic peak in spectra of Span 80 was at $1736 \mathrm{~cm}^{-1}$, and the characteristic peak in spectra of Tween 60, Tween 80 and physical mixture 1 was at $1734 \mathrm{~cm}^{-1}$. All these peaks indicate the aldehyde functional group respectively.

Span 80 showed the characteristic peak at 1736 $\mathrm{cm}^{-1}$ which indicates the esters functional group. Tween 80 showed the characteristic peak at $2856 \mathrm{~cm}^{-1}$ which indicates the Carboxylic acids functional group. Hexa decyl pyridinium chloride showed the characteristic peaks at $3367 \mathrm{~cm}^{-1}$, $1635 \mathrm{~cm}^{-1}, 1471 \mathrm{~cm}^{-1}$, and at $1177 \mathrm{~cm}^{-1}$. These peaks indicate Amines or hydroxyl group, Secondary amine or conjugated ketone, carbonate ion, and secondary amine functional group respectively $[15,16]$.

\section{Size and zeta potential}

The mean size and PDI of niosomal formulations is given in Table 5 . It indicates that by changing the surfactant to cholesterol level in different formulations, the size of niosomes is also affected significantly (ANOVA, p <0.05). The mean size of niosomes of the selected formulation $\left(F_{2}\right)$ was $1049.3 \times 10^{-3} \mu \mathrm{m}$.

The zeta potential of the selected formulation $\left(F_{2}\right)$ was $9.40 \pm 0.18(\mathrm{mV})$

\section{Morphology of niosomes}

Scanning electron microscopy (SEM) was employed in the morphological study. In figure 4, the SEM image of the optimized niosomal formulation $\mathrm{F}_{2}$ is demonstrated. The spherical shape of the niosomes is depicted in Figure 4.

\section{Drug entrapment}

Niosomes were separated using ultracentrifu- gation, and the amount of Cyclosporine $A$ in different formulations is provided in Table 6.

Table 5: Mean size and polydispersity index of niosomal formulations

\begin{tabular}{lcc}
\hline $\begin{array}{l}\text { Formulation } \\
\text { code }\end{array}$ & Size $(\boldsymbol{\mu m})$ & $\begin{array}{c}\text { Polydispersity } \\
\text { index }\end{array}$ \\
\hline $\mathrm{F}_{1}$ & $\begin{array}{c}436.1 \times 10^{-3} \pm \\
0.141\end{array}$ & $0.451 \pm 0.04$ \\
$\mathrm{~F}_{2}$ & $1049.3 \times 10^{-3} \pm$ & $0.435 \pm 0.15$ \\
$\mathrm{~F}_{3}$ & 0.117 & \\
$\mathrm{~F}_{4}$ & $\begin{array}{c}534.7 \times 10^{-3} \pm \\
0.215\end{array}$ & $0.471 \pm 0.06$ \\
$\mathrm{~F}_{5}$ & $415.2 \times 10^{-3} \pm$ & $0.356 \pm 0.11$ \\
$\mathrm{~F}_{6}$ & 0.311 & \\
& $424.1 \times 10^{-3} \pm$ & $0.481 \pm 0.17$ \\
& 0.185 & \\
\hline & $673.8 \times 10^{-3} \pm$ & $0.572 \pm 0.21$ \\
\hline
\end{tabular}

Data are mean \pm standard deviation; in all formulations, size of the niosmes was significantly different from each other $p<0.05$

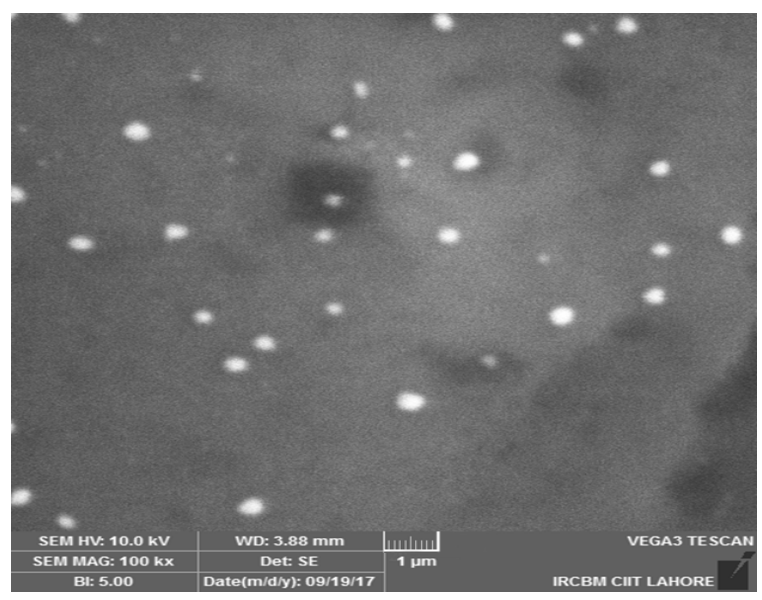

Figure 4: SEM image of optimized formulation $F_{2}$

Table 6: Mean entrapment efficiency of niosomal formulations

$\begin{array}{lcl}\begin{array}{l}\text { Formulation } \\ \text { code }\end{array} & \begin{array}{c}\text { Surfactant: } \\ \text { cholesterol ratio }\end{array} & \begin{array}{l}\text { Entrapment } \\ \text { efficiency (\%) }\end{array}\end{array}$

\begin{tabular}{lcc} 
& Tween 60+Span 60: cholesterol \\
$\mathrm{F}_{1}$ & $7: 3$ & $26.88 \pm 0.43$ \\
$\mathrm{~F}_{2}$ & $6: 4$ & $77.28 \pm 0.35$ \\
$\mathrm{~F}_{3}$ & $5: 5$ & $52.08 \pm 0.38$ \\
& Tween $\mathbf{8 0}+$ Span $80:$ cholesterol \\
$\mathrm{F}_{4}$ & $7: 3$ & $63.84 \pm 0.41$ \\
$\mathrm{~F}_{5}$ & $6: 4$ & $56.12 \pm 0.52$ \\
$\mathrm{~F}_{6}$ & $5: 5$ & $43.68 \pm 0.39$ \\
\hline
\end{tabular}

Data are mean \pm standard deviation; in all niosomal formulations, entrapment efficiency was significantly different from each other $p<0.05$

\section{DISCUSSION}

Niosomal formulations were successfully developed at various ratios of surfactant and 
cholesterol (Table 1) using thin film hydration technique.

ATR-FTIR spectra of individual components are shown in Figure 1.Characteristic peaks in the FTIR spectrum of cyclosporine A are given in Table 2 . These are similar to peaks as given in literature, which indicates the purity of this sample and indicates that impurities are not present [17].

ATR-FTIR spectra of physical mixture 1 (PM1) and physical mixture 2 (PM2) are shown in Figure 2. Physical mixtures of cyclosporine $A$ with cholesterol and nonionic surfactants were prepared by simple mixing in equimolar ratios. Characteristic peaks of physical mixtures 1 \& 2 are given in Table 3. The FTIR spectrum shows similar peaks in spectra of physical mixtures as in an individual spectrum of pure ingredients. The spectrum of physical mixtures did not show a significant shift of peaks which indicates that there were no interactions.

The ATR-FTIR spectrum of niosomal formulations are shown in Figure 3. It showed similar peaks and the marked reduction of IR bands of drugs as well as the intensity of peaks. The characteristic peaks with corresponding functional groups are given in Table 4. Due to the formation of niosomes, most of the peaks are diffused, demonstrating a strong physical interaction between cholesterol, drugs, and surfactants. The lack of a significant shift of a new peak indicates a lack of chemical interaction. So, it depicts that cyclosporine A is intact and can show its therapeutic effect.

The size and polydispersity index of the niosomes of different formulations are given in Table 5. The size of the niosomes were significantly different from each other $(p<0.05)$. In formulation $F_{2}$, Span 60 was used. It had a critical packing parameter in the range of 0.5 to 1 and can be used in niosomal formulations [18]. The SEM image of optimized formulation $\mathrm{F}_{2}$ shows the spherical shape of niosomes in our study as shown in Figure 4, which is also similar to the naltrexone niosomes made by using Span 60 [19].

Different studies of niosomes showed that the cholesterol concentration is increased up to some extent, i.e. entrapment efficiency increases from 0 to $50 \%[20,21]$. In formulations $F_{1}$ to $F_{3}$, the surfactants used were Span 60 and Tween 60 , and the concentration of cholesterol was gradually increased from 30 to $50 \%$ as shown in Table 1. The maximum entrapment of $77.28 \%$ was achieved in formulation $F_{2}$ as shown in Table 6. In which surfactants and cholesterol were in the ratio of $6: 4$. Therefore, $40 \%$ cholesterol shows maximum entrapment efficiency. Statistical analysis of data given in Table 6 indicated that the percentage of entrapment efficiency was dependent significantly on surfactant to cholesterol ratio in the niosomal formulations (ANOVA; $p<0.05$ ).

The minimum amount of cholesterol necessary to form vesicles increases as the HLB of surfactants increases above 10. In $F_{2}$, the mixed surfactant system is used, i.e. Tween $60+$ Span 60 is used instead of a single surfactant. This combination helps in increasing the entrapment efficiency of cyclosporine A. This mixed surfactant system was also used in another study to increase the entrapment efficiency of the poorly soluble drug named diacerein. They used sorbitan monolaurate and poloxamer 184 as a mixed surfactant, and this resulted in the increased entrapment efficiency of diacerein [22].

In formulations $F_{4}$ to $F_{6}$, the surfactants used were Tween 80 and Span 80 , while in $F_{4}$ the cholesterol concentration was $30 \%$ as shown in Table 1. Among these formulations $F_{4}$ to $F_{6}$, maximum entrapment $63.84 \%$ was achieved in $\mathrm{F}_{4}$ as shown in Table 6. Consequently, it has been shown with regard to this surfactant system that further increasing the cholesterol concentration up to $50 \%$ does not increase the entrapment efficiency.

In $\mathrm{F}_{3}$ and $\mathrm{F}_{6}$, the cholesterol concentration was the highest: up to $50 \%$, but the entrapment efficiency was less. The reason for this fact may be that the higher concentration of cholesterol causes the disruption of niosomes, leading to the leakage of the drug [23]. The data given in Table 6 shows that the percentage of entrapment efficiency is highly dependent on the amount of surfactant and amount of cholesterol which is used in appropriate ratios in different formulations.

\section{CONCLUSION}

The niosomal formulation of cyclosporine $A$ has successfully been developed with the aid of cholesterol and non-ionic surfactants. Niosomal formulation $F_{2}$ based on the nonionic surfactant to cholesterol ratio (6:4) indicates the maximum entrapment of cyclosporine A (77.28\%). There is no incompatibility or interaction between the ingredients of the niosomal formulation. Thus, these niosomes can be used to enhance the bioavailability of cyclosporine $A$.

\section{DECLARATIONS}

\section{Acknowledgement}

Trop J Pharm Res, August 2018; 17(8): 1463 
The authors thank Dr Muhammad Sher, who is in-charge of the Hi-Tech Lab, University of Sargodha for his kind support and guidance.

\section{Conflict of Interest}

No conflict of interest associated with this work.

\section{Contribution of Authors}

The authors declare that this work was done by the authors named in this article and all liabilities pertaining to claims relating to the content of this article will be borne by them.

\section{REFERENCES}

1. Marianecci C, Di Marzio L, Rinaldi F, Celia C, Paolino D, Alhaique $F$, Esposito S, Carafa M. Niosomes from $80 \mathrm{~s}$ to present: the state of the art. Adv Colloid Interface Sci 2013; 05: 187-206.

2. Walker $R$, Whittlesea C. Clinical pharmacy and therapeutics. 4th edn., Edinburgh: Churchill Livingstone; 2007. p. 35-36.

3. Katzung BG, Masters SB, Trevor AJ. Basic and clinical pharmacology. 11th edn., Singapore: McGraw-Hill Education; 2009. p. 630-631.

4. Sean CS. Martindale: The complete drug reference (36th edn). London: Pharmaceutical Press; 2009. p. 18221833.

5. Kim C, Ryuu S, Park K, Lim S, Hwang S. Preparation and physicochemical characterization of phase inverted water/oil microemulsion containing cyclosporine $A$. Int $J$ Pharm 1997; 147(1): 131-134.

6. Guan $P, L u Y, Q i$ J, Niu M, Lian R, Hu F, Wu W. Enhanced oral bioavailability of cyclosporine $A$ by liposomes containing a bile salt. Int $J$ Nanomedicine; 2011; 6: 965-974.

7. Rus LM, Tomuta I, Luga C, Maier C, Kasco I, Borodi G, Bratu I, Bojita M. Compatibility of indapamide/pharmaceutical excipients used in tablet preformulation. Farmacia 2012; 60(1): 92-101.

8. Hind AR, Bhargava SK, McKinnon A. At the solid/liquid interface: FTIR/ATR the tool of choice. Adv Colloid Interface Sci 2001; 93: 91-114.

9. Khan MI, Madni A, Ahmad S, Khan A, Rehman M, Mahmood MA. ATR-FTIR based pre and post formulation compatibility studies for the design of niosomal drug delivery system containing nonionic amphiphiles and chondroprotective drug. J Chem Soc Pak 2015; 37(03): 527-533.

10. Khan MI, Madni A, Ahmad S, Mahmood MA, Rehman M, Ashfaq M. Formulation design and characterization of a non-ionic surfactant based vesicular system for the sustained delivery of a new chondroprotective agent. Braz J Pharm Sci 2015; 51(3): 607-615.

11. Barakat HS, Kassem MA, El-Khordagui LK, Khalafalla NM. Vancomycin- eluting niosomes: a new approach to the inhibition of staphylococcal biofilm on abiotic surfaces. AAPS PharmSciTech 2014; 15(5): 12631274.

12. Lee MK, Choi L, Kim MH, Kim CK. Pharmacokinetics and organ distribution of cyclosporine $A$ incorporated in liposomes and mixed micelles. Int J Pharm 1999; 191 : 87-93.

13. Ping JGQ, Jiao GSC. Lecithin vesicular carrier for transdermal delivery of cyclosporine A. Int $J$ Pharm 1999; 194: 201-207.

14. Nikouei BM, Banaee T, Aghamohammadian J, Mosallaei $N$, Mohajeri SA. Quantitative LC analysis of cyclosporine $A$ in ocular samples. Chromatographia 2011; 73: 817821.

15. Coates J. Interpretation of infrared spectra, a practical approach. Encyclopedia of Analytical Chemistry 2000. 10815-10837.

16. Glagovich N. IR Absorptions for Representative Functional Groups, 2005. Available from: http://instruction.greenriver.edu/kmarr/Chem\%20162/Ch em162\%20Labs/Interpreting\%20IR\%20Spectra/IR\%20A bsorptions\%20for\%20Functional\%20Groups.htm.

17. Silverstein MR. In spectrometric identification of organic compounds, New York: John Wiley \& Sons; 2005; $p$ 76108.

18. Uchegbua IF, Vyasb SP. Non-ionic surfactant based vesicles (niosomes) in drug delivery. Int J Pharm 1998; 172(1-2): 33-70

19. Abdelkader H, Wu Zimei, Al-Kassas $R$, Alany $R$. Niosomes and discomes for ocular delivery of naltrexone hydrochloride: morphological, rheological, spreading properties and photo-protective effects. Int $\mathrm{J}$ Pharm 2012; 433(1-2): 142-148.

20. Mali N, Darandale S, Vavia P. Niosomes as a vesicular carrier for topical administration of minoxidil: formulation and in vitro assessment. Drug Deliv Trans/ Res 2013; 3(6): 587-592.

21. Teja SSP, Mothilal M, Damodharan N, Jaison $D$. Screening and optimization of valacyclovir niosomes by design of experiments. Int J App Pharm 2017; 10(1): 79-85.

22. Khan MI, Madni A, Peltonen L. Development and in-vitro characterization of sorbitan monolaurate and poloxamer 184 based niosomes for oral delivery of diacerein. Eur $\mathrm{J}$ Pharm Sci 2016; 95: 88-95.

23. Abdelkader $\mathrm{H}$, Ismail $S$, Kamal A, Alany R. Preparation of niosomes as an ocular delivery system for naltrexone hydrochloride: Physicochemical characterization. Pharmazie 2010; 65(11): 811-817. 